\title{
Metaphyseal dysostosis-intellectual disability-conductive deafness syndrome
}

INSERM

\section{Source}

INSERM. (1999). Orphanet: an online rare disease and orphan drug data base. Metaphyseal dysostosis-intellectual disability-conductive deafness syndrome. ORPHA:2502

Metaphyseal dysostosis-intellectual disability-conductive deafness syndrome is characterised by metaphyseal dysplasia, short-limb dwarfism, mild intellectual deficit and conductive hearing loss, associated with repeated episodes of otitis media in childhood. It has been described in three brothers born to consanguineous Sicilian parents. Variable manifestations included hyperopia and strabismus. The mode of inheritance is autosomal recessive. 